\title{
COMUNICACIÓN PUBLICITARIA EN EL MONASTERIO CISTERCIENSE DE NUESTRA SEÑORA DE MONSALUD EN CÓRCOLES (GUADALAJARA) ${ }^{1}$
}

\author{
POR \\ JaVier De SAntiago Fernández \\ Catedrático de Epigrafía y Numismática, Departamento de Ciencias y \\ Técnicas Historiográficas, Facultad de Geografía e Historia, UCM
}

\begin{abstract}
RESUMEN
En el presente artículo se estudia la intención publicitaria de las inscripciones del Monasterio de Nuestra Señora de Monsalud en Córcoles. Se investiga acerca del uso que de la producción epigráfica se hizo en este monasterio cisterciense. Para ello se relacionan las inscripciones con las características del movimiento cisterciense. También se analiza minuciosamente la escritura de los epígrafes, lo cual ha permitido retrasar la cronología de uno de ellos, posterior a la indicada en su data.
\end{abstract}

Palabras Clave: Epigrafía, Monasterio de Monsalud, Comunicación publicitaria.

\section{PUBLICITARY COMMUNICATION IN THE CISTERCIAN MONASTERY OF «NUESTRA SEÑORA DE MONSALUD» IN CÓRCOLES (GUADALAJARA)}

\begin{abstract}
This paper studies the publicitary intention of the inscriptions of the Monastery of «Nuestra Señora de Monsalud» in Córcoles. We investigate the use of
\end{abstract}

\footnotetext{
${ }^{1}$ Este trabajo se inscribe dentro de los Proyectos de Investigación Corpus Inscriptionum Hispaniae Mediaevalium II (HUM 2007-62932/HIST) y Corpus Inscriptionum Hispaniae Mediaevalium III (HAR2010-16629), financiados respectivamente por los Ministerios de Educación y Ciencia y Ciencia e Innovación.
} 
epigraphic production in this Cistercian monastery. To this end, these inscriptions are related to the characteristics of the Cistercian movement. Also, we analyze in detail the writing on these epigraphs. This study has allowed us to bring forward the era of one of these, to a time later than that indicated in the text itself.

KEY WORDS: Epigraphy, Monastery of Monsalud, publicitary communication.

Recibido/Received 2011-05-24

Aceptado/Accepted 2112-01-05

Parece conveniente comenzar este artículo con una justificación del título, que obedece al concepto actual de Epigrafía, definida como la ciencia que estudia los objetos escritos realizados en orden a una publicidad universal y permanente, según la definió Robert Favreau. ${ }^{2}$ Son las inscripciones, por tanto, escritos que pretenden la publicidad, hacer llegar su mensaje al público más amplio que sea posible dentro del contexto en el que se ubican, en este caso un monasterio cisterciense, por lo que será mayoritariamente la comunidad monástica la destinataria del mensaje. Es por ello por lo que hablamos de comunicación publicitaria en el monasterio de Monsalud.

Se alzan las ruinas del monasterio de Nuestra Señora de Monsalud en las proximidades de la localidad guadalajareña de Córcoles. A pesar de su estado ruinoso, ha sido definido «como el más completo y espectacular de los monasterios medievales de la tierra alcarreña». ${ }^{3}$ Esta afirmación, que hace justicia al conjunto arquitectónico conservado, se realza por la existencia y preservación in situ de un conjunto epigráfico de interés, destacando en especial la consecra$t_{i o}{ }^{4}$ de un altar, el que estuvo situado en uno de los ábsides laterales. Cuenta, además, el monasterio con otras tres inscripciones, situadas en el claustro, las tres epitaphia sepulcralia. ${ }^{5}$ Añadimos un monumentum dotationis, ${ }^{6}$ transmitido por Ângel Manrique, ${ }^{7}$ cronista de la Orden del Císter, y por el P. Cartes, ${ }^{8}$ monje

\footnotetext{
${ }^{2}$ Favreau, R. 1979. Les inscriptions médiévales: 16. Turnhout.

${ }^{3}$ Herrera Casado, A. 1997. Monasterios medievales de Guadalajara: 69. Guadalajara.

${ }^{4}$ Empleo, al referirme a los diferentes tipos de inscripciones, la tipología y nomenclatura acuñadas por Vicente García Lobo y María Encarnación Martín López, sintetizadas en un trabajo reciente (García Lobo, V. y Martín López, M. E. 2009. «La Epigrafía medieval en España. Por una tipología de las inscripciones» en J. C. Galende Díaz y J. de Santiago Fernández (dirs.), VIII Jornadas Científicas sobre Documentación de la Hispania altomedieval: 185-213. Madrid). En este trabajo la consecratio queda definida como aquella inscripción que recoge la noticia de la consagración de una iglesia o un altar.

${ }^{5}$ Inscripciones que «recogen la noticia del enterramiento de una persona» (García Lobo, V. y Martín López, M. E. 2009: 191).

${ }^{6}$ «Aluden a la dotación económica de una institución» (García Lobo, V. y Martín López, M. E. 2009: 193).

${ }^{7}$ Manrique, A. 1642-1659. Cisterciensium seu verius ecclesiasticorum annalium a condito Cistercio: vol. I, cap. IX, 415. Lyon.

${ }^{8}$ Cartes, Fr. B. de. 1721. Historia de la milagrosa imagen de Nuestra Señora de Monsalud: 101. Alcalá.
}

Hispania Sacra, LXIV

129, enero-junio 2012, 67-96, ISSN: 0018-215-X, doi: 10.3989/hs.2012.003 
e historiador del monasterio del siglo XVIII, epígrafe que ha suscitado notables sospechas entre los investigadores y estudiosos más recientes, quienes no han dudado en calificarlo como falso.

Es de destacar, entre todas las inscripciones, la consecratio. Su importancia viene dada por diversos motivos. En primer lugar, se trata de la única inscripción medieval existente en toda la provincia de Guadalajara alusiva a la ceremonia litúrgica de la consagración. Su singularidad se acrecienta por hallarse en un monasterio cisterciense, dada la parquedad que en lo referente al hábito epigráfico suelen presentar las fundaciones realizadas por la Orden del Císter, muy especialmente en lo relativo a consecrationes. Por último, constituye un documento, hasta ahora no aprovechado, en el estudio de la historia del monasterio.

Como acabo de señalar, los monasterios cistercienses no se mostraron especialmente proclives a la producción epigráfica, al contrario de lo que sucedió con el modelo benedictino, que realizó un uso consciente y, en muchos casos, abundante de las inscripciones como instrumento de comunicación publicitaria. Es algo motivado por las propias características del movimiento cisterciense que, como es de sobra conocido, tuvieron una notable repercusión en sus manifestaciones artísticas, caracterizadas por la austeridad, la sencillez, la pureza de formas, con ausencia de elementos decorativos, figurativos o superfluos, todo lo cual sirve para traducir el rigorismo en la aplicación de la regla de San Benito, eliminando de ella dulcificaciones y dispensas, y la vuelta a la pureza en la liturgia y en la tradición monástica, con el retorno a la estricta vida contemplativa predicada por los monjes blancos. Su nueva espiritualidad estuvo basada en la soledad y en la pobreza, combinando en su modo de vida la oración y el trabajo manual. Su máxima es una vida libre de todo lo superfluo. Esto queda reflejado hasta en su hábito, que, como símbolo de austeridad, sería de lana sin teñir, por tanto blanco, y en sus usos alimenticios, en los que se prescinde de la carne.

Lo mismo sucedió en las manifestaciones arquitectónicas y artísticas. San Bernardo, en su Apología al abad Guillermo de Saint Thierry, se pronunció en contra del lujo y de las grandes dimensiones de los templos. Para él los monjes no necesitaban esculturas, pintura o adornos para reflexionar sobre la ley de Dios. Son clarificadoras acerca de sus ideas las siguientes frases: «la suntuosidad de sus pulimentadas ornamentaciones y de sus originales pinturas -está hablando de los templos- que atraen la atención de los que allí van a orar, pero quitan hasta la devoción [...] ¿qué buscan con todo esto? ¿La compunción de los convertidos o la admiración de los visitantes? Vanidad de vanidades. ¿Vanidad o insensatez?». ${ }^{9}$

\footnotetext{
${ }^{9}$ Citado por Muñoz Párraga, M. C. 1998. «La iglesia» en Monjes y Monasterios. El Císter en el medievo de Castilla y León: 107. Valladolid.
} 
San Bernardo consideraba que el arte era una fuente de gastos superfluos y de vanas y absurdas distracciones y sus escritos, junto a los de Aelredo, abad de Rievaulx, en Inglaterra, propiciaron la ausencia de manifestaciones artísticas en los edificios de culto. Ambos rechazaron el halago sensorial que conllevaba la didáctica visual anterior en pro de la contemplación y meditación de las Escrituras. ${ }^{10}$ En esa línea, en 1134 los estatutos del Capítulo General prohibieron la ejecución de pinturas y esculturas en los monasterios, debido a la consideración de que mirarlas se prestaba a negligencias en la meditación y en la disciplina de la seriedad religiosa. ${ }^{11}$

Estas ideas y realidades relacionadas con la producción artística en general tuvieron aplicación también en lo que se refiere a la producción epigráfica, tan utilizada en las abadías benedictinas. Como en el caso de pinturas y esculturas, los monjes y los monasterios cistercienses tampoco precisaban de inscripciones. El espíritu de simplicidad es contrario a toda monumentalidad y, por tanto, a cualquier forma de comunicación publicitaria, a lo que se añade al predicado retorno hacia el mundo interior. Una vez más se intenta eliminar todo aquello que pudiese distraer al monje en su búsqueda de Dios. ${ }^{12}$ Eso es lo que ha llevado a los profesores García Lobo y Martín López a calificar al modelo de producción epigráfica propia de los cenobios surgidos de la reforma de San Bernardo de escaso, poco funcional e historicista.

Lo primero se comprueba fácilmente. Basta comparar, desde un punto de vista cuantitativo, la producción monástica benedictina con la cisterciense. El segundo se refiere a que los cistercienses no aprovechan todas las posibilidades comunicativas que el epígrafe ofrece, pues entre los tipos de inscripciones existentes se observa la ausencia de aquellos con una función que puede ser denominada como pedagógico-doctrinal, catequética y moralizante; se centran fundamentalmente, y vamos al tercer elemento, en inscripciones que pretenden la memoria histórica. ${ }^{13}$

Esa memoria histórica, conseguida a base de inscripciones que recuerdan hechos fundamentales para el monasterio, como en el caso de Monsalud, son la donación del monasterio por parte del rey Alfonso VII, la consagración de un altar o la muerte de insignes personajes que acreditan la vinculación del monasterio con la Orden de Calatrava, sirve para aglutinar a los miembros de la

\footnotetext{
${ }^{10}$ Pérez-Embid, J. 1986. El Císter en Castilla y León. Monacato y dominios rurales (s. XII-XV): 129-130. Valladolid.

${ }^{11}$ Esta prohibición ya había sido realizada en el Capítulo de 1119, pero ahora se recogen los motivos por los que se hace, muy en la línea de las ideas de San Bernardo.

${ }^{12}$ Martín López, M. E. 2007. «La publicidad en el nuevo monacato del siglo XII» en El monacato en los reinos de León y Castilla (siglos VII-XIII): 460-461. Ávila.

${ }^{13}$ García Lobo, V. y Martín López, M. E. 1998. «La publicidad en el Císter» en I. G. Bango Torviso (dir.), Monjes y monasterios. El Císter en el medievo de Castilla y León: 55. Valladolid.
} 
comunidad y consolidar la Orden. ${ }^{14}$ Ya señalaron García Lobo y Martín López como los epitaphia y los monumenta constituyen los tipos más universales y constantes de inscripciones en los cenobios cistercienses. ${ }^{15}$ El monasterio de Nuestra Señora de Monsalud se adapta perfectamente a ese modelo.

\section{EL MONUMENTUM DOTATIONIS ${ }^{16} \mathrm{Y}$ EL ORIGEN DEL MONASTERIO}

El monumentum dotationis ofrece la fecha de 1140 como la de fundación del monasterio, pero los orígenes de éste son discutidos, fundamentalmente como consecuencia de la desaparición de su archivo debido a un incendio en 1437 y a las dudas que ha despertado la inscripción. En realidad estamos ante uno de los monasterios peor conocidos del Císter hispano. Las fechas acerca de su fundación, ofrecidas por los diversos autores, varían bastante: oscilan entre 1138 y 1167 , y se apoyan en muy diferentes, y algunos de ellos cuestionables, razonamientos. ${ }^{17}$

La inscripción estuvo ubicada «en la capilla mayor deste monasterio, al lado del Evangelio, debajo del real escudo do las armas del emperador D. Alonso, adorna y hermosea la pared». ${ }^{18}$ En la actualidad en tal ubicación no queda vestigio alguno ni del epígrafe ni del escudo, pero en el lado de la Epístola, en la parte alta, hay dos espacios rellenos con yeso que perfectamente hubieran podido albergar escudo e inscripción.

Según la información que transmite Cartes, el epígrafe tomó su texto de un documento existente en el archivo de Escala $\operatorname{Dei}^{19}{ }^{19}$ en el del propio monasterio, para añadir a continuación «papel que es de todas maneras auténtico». ${ }^{20}$ Cartes basa su teoría de la fundación en 1140 en este testimonio epigráfico, el documento en el que supuestamente se inspira y diversas noticias procedentes del tumbo viejo del monasterio. ${ }^{21}$

${ }^{14}$ Martín López, M. E. 2007: 463.

${ }^{15}$ García Lobo, V. y Martín López, M. E. 1998: 50.

${ }^{16}$ Apéndice epigráfico, núm. 1.

${ }^{17}$ Un buen estado de la cuestión sobre el tema en Díaz Ibáñez, J. 1995. «Santa María de Monsalud. Reconstrucción histórica de un cenobio cisterciense», Cistercivm 201: 361-369; también Álvarez Palenzuela, V. A. 1978. Monasterios cistercienses en Castilla (siglos XII-XIII): 111-114. Valladolid.

${ }^{18}$ Cartes, Fr. B. de. 1721: 101.

${ }^{19}$ Monasterio cisterciense ubicado en la Gascuña. Los fundadores de Monsalud fueron monjes procedentes de Escala Dei.

${ }^{20}$ Cartes, Fr. B. de. 1721: 101.

${ }^{21}$ Probablemente se refiera al terminado de redactar en junio de 1560 por fray Julián Martínez, monje de Monsalud, conservado en Archivo Histórico Nacional (en adelante AHN), Clero, libro 4.325. 
Efectivamente se indica en el tumbo que la fundación fue «el año de la Encarnación de Nuestro Señor Ihesu Christo de mill y ciento y quarenta» ${ }^{22}$ y se da como fundador al «rey don Alonso, el octavo deste nombre, que (...) se llamó emperador de España, padre del rey don Sancho el deseado». ${ }^{23}$ En esa misma línea se cita un privilegio ${ }^{24}$ que confirma otro del «rey don Alonso el octavo, que se llamó emperador de España, bisabuelo del bisabuelo de éste, que confirma que fue el que fundó este monasterio». ${ }^{25} \mathrm{Al}$ hacer una relación de las escrituras quemadas en el incendio que acabó con el archivo, el tumbo menciona un privilegio, dado por el Papa Inocencio IV que se data «En Roma XII kalendas octobris año del Señor de mill dozientos y cinquenta, ciento y diez años después de la fundación deste monasterio». ${ }^{26}$ Junto al documento de donación por parte del arcediano de Huete al monasterio, correspondiente a 1167, al margen, se indica «reynando el rey don Alonso el $9^{\circ}$, nieto del fundador», además de señalar que esto no fue sino una confirmación de la donación anterior. ${ }^{27}$

Indica Cartes que en el tumbo, junto a la donación del arcediano de Huete, fray Jerónimo de Llamas ${ }^{28}$ anotó que no fue fundación, sino aumento, existiendo desde antes el monasterio, que remonta a la época de Alfonso VII. ${ }^{29}$ Esta anotación hubo de ser hecha, aunque Cartes no lo especifica, en el tumbo nuevo, realizado en 1587 por fray Ambrosio López, ${ }^{30}$ dado que se supone que fray Jerónimo nació en torno a $1550-1553 .{ }^{31}$ Cita, por último, a fray Bernardo de Villalpando, quien habría dejado escrito al final del tumbo nuevo que el monasterio de Monsalud fue fundado por monjes procedentes de Escala Dei en un sitio diferente del definitivo, gracias a donaciones efectuadas por Alfonso VII en el lugar llamado de Villafranca, afirmaciones que apoyaba en información trans-

\footnotetext{
${ }^{22}$ AHN, Clero, libro 4.235, fol. 1v.

${ }^{23}$ Ibídem, fols. 1v.-2r. Obviamente se está refiriendo a Alfonso VII, si bien se le cita como «el octavo deste nombre», seguramente por incluir en el cómputo a Alfonso el Batallador, marido de la reina doña Urraca.

${ }^{24}$ Se trata del privilegio de confirmación de la donación del arcediano de Huete.

${ }^{25} \mathrm{AHN}$, Clero, libro 4.235, fols. 10r-11r.

${ }^{26}$ Ibídem, fol. 9r.

${ }^{27}$ Ibídem, fol. 13 r.

${ }^{28}$ Fray Jerónimo de Llamas fue un ilustre historiador de la Orden del Císter, autor de un tratado sobre el monasterio de Carracedo y otros cenobios cistercienses; incluso dejó escrita en su monasterio, Carracedo, del que fue abad entre 1593 y 1596, una obra titulada Anales del Císter (Yáñez, Fr. D. 1991. «En el milenario de Carracedo». Cistercivm XLIII/184: 24-30).

${ }^{29}$ Cartes, Fr. B. de. 1721: 109. «Esta no fue fundación, sino aumento y melioración, que hizo don Juan de Tréberes, pues presupone aver ya convento de Monsalud, con abad y monges que sirven a Dios en el dicho monasterio, guardando la Regla de San Benito, y assí la fundación deste monasterio primera no es ésta, sino que fue del señor rey don Alonso VII, que fue coronado Emperador en León, que fue el nieto del que ganó Toledo y abuelo deste Señor rey Don Alonso VIII o Bueno o Noble. Advierto esto para que no se equivoque. Fray Gerónimo de Llamas».

${ }^{30}$ Fray Ambrosio López fue General de la Orden y antes abad de Monsalud.

${ }^{31}$ Yáñez, Fr. D. 1991: 26.
} 
mitida por el tumbo. ${ }^{32}$ Concluía fray Bernardo su exposición con la siguiente aseveración «y que haya avido allí monasterio confírmalo no sólo la tradición de esta casa, sino también el tumbo antiguo de ella, donde se dize, avía allá monges y dormitorio».

En relación con esto último se ha defendido que el primer asentamiento del monasterio tuvo lugar en una ermita que, al parecer, tenía un antiguo pasado de tradición religiosa, ubicada en los peñascales del madroñal de Auñón, paraje antes llamado Villafranca, cerca del actual pantano de Entrepeñas. Supuestamente los monjes se habrían instalado allí dos años antes de establecerse en la ubicación definitiva de los actuales restos del monasterio, a donde se habrían trasladado por la dureza del terreno y la falta de agua de la ubicación primigenia, condiciones poco adecuadas para las necesidades de un monasterio.

Obviamente, los datos de Cartes y del tumbo no pueden darse por ciertos y evidentemente no todo está tan claro. De hecho, el propio Cartes indica que en el tumbo nuevo fray Ambrosio López concluyó en el folio 41 que el fundador del monasterio fue el arcediano de Huete en 1167, si bien Cartes intenta desacreditar esta idea. ${ }^{33}$ De ser cierta la afirmación de fray Ambrosio, la veracidad de los datos de la inscripción, y también la del tumbo viejo, quedaría puesta en entredicho.

Precisamente dudas es lo que manifiesta sobre la cronología del cenobio, y por tanto sobre la inscripción Ángel Manrique, quien se inclina más por 1141 como año de fundación, por ser éste el recogido en las tablas cronológicas del Císter. ${ }^{34}$ Esta fecha de 1141 es también seguida por fray Antonio de Yepes. ${ }^{35}$

Álvarez Palenzuela no duda en calificar la inscripción de falsa, al tiempo que se opone a una fundación tan temprana como la propuesta por Cartes, como ya antes habían hecho García López y Pérez Villamil. ${ }^{36}$ La retrasa hasta 1165 o 1167, opinión que también defiende Abad Castro. ${ }^{37}$ El primer año sería el de la

\footnotetext{
${ }^{32}$ Cartes, Fr. B. de. 1721: 114-115. «monges de aquel monasterio [Escala Dei] salieron a fundar este de Monsalud a otro sitio diferente del que aora tiene (aunque no le nombra), pero por una donación yo vi en el Tumbo del dicho monasterio, donde están todas las que le fueron hechas, (la qual se ha perdido en esta casa o quemado) por el Emperador don Alonso al abad que entonces era de aquel monasterio del territorio de Villafranca, para que en él fundasse un monasterio de su Orden, a la qual según decía allí el Emperador tenía particular afición, parece fue dentro del término de una granxa, que se decía Villafranca».

${ }^{33}$ Ibídem: 107.

${ }^{34}$ Las tablas cronológicas del Císter tampoco parecen demasiado fiables y se han constatado diversos errores en ellas (Álvarez Palenzuela, V. A. 1978: 112).

${ }^{35}$ Yepes, Fr. A. de. 1960. Crónica General de la Orden de San Benito: vol. III, 334. Madrid [reedición de la edición de 1609-1621].

${ }^{36}$ García López, J. C. y Pérez Villamil, M. 2002. Relaciones Topográficas de la provincia de Guadalajara. Aumentos, Córcoles. Guadalajara [2ª edición en CD Rom; $1^{\text {a }}$ edición Madrid, 1908-1911].

${ }^{37}$ Abad Castro, C. 1990. «Monasterio de Monsalud de Córcoles (Guadalajara)». Anuario del Departamento de Historia y Teoría del Arte (U.A.M.) II: 47-50.
} 
instalación en el madroñal de Auñón y el segundo el de la definitiva ubicación junto a Córcoles. Para ello se apoya fundamentalmente en el primer documento conocido y cierto que alude al monasterio, el cual corresponde a junio de 1167. Se trata de una carta de donación, antes citada, realizada por Juan, Arcediano de Huete, por la cual le concede «aldeam que dicitur Corcoles», ${ }^{38}$ donación confirmada por el monarca Alfonso VIII dos años después. ${ }^{39}$ Esos territorios habrían sido la base para la fundación del monasterio.

Argumenta Álvarez Palenzuela, para reforzar su idea, que los años pasados entre 1140 o 1141 y 1167 son demasiados para no tener noticia documental alguna de un monasterio que si bien era pequeño, no lo era tanto como para explicar tal vacío documental. Igualmente, señala que es preciso tener en cuenta que el monasterio de Escala Dei fundó Fitero en 1140 y Sacramenia en 1141; de haber fundado Monsalud, también en esos años sus monjes habrían dado lugar a tres monasterios en tan solo tres años, lo cual supone una enorme capacidad regenerativa por parte de la casa madre, dado que, según la Regla, el número mínimo de monjes para realizar la vida monástica era 12 y parece que eso se cumplió de manera tajante al principio, ${ }^{40}$ si bien Cartes cita sólo a tres monjes procedentes de Escala Dei como los fundadores, Fortunio Donato, Raimundo y Bueno Emeilino, ${ }^{41}$ lo cual parece, si atendemos al cumplimiento de la Regla, inverosímil.

El razonamiento de Álvarez Palenzuela para calificar la inscripción como falsa descansa más en datos históricos que en el propio epígrafe. Sin embargo, su argumentación tampoco es definitiva, como reconoce el propio autor. La donación del arcediano de Huete prueba la existencia de la comunidad monástica en 1167, pero quizá pudiera coincidir simplemente con el traslado de los monjes desde su primigenia ubicación, siendo, eso sí, el origen de la instalación en el lugar donde se hallan sus ruinas, o quizá no fuese más que una donación a una comunidad ya existente. Tampoco es irrefutable la ausencia documental entre 1140 y 1167 , pues es sabido el peligro de las teorías basadas en argumentos $e x$ silentio. Asimismo, aunque es un razonamiento lógico e indicativo, no es concluyente el dato de la fundación de tres monasterios en dos años, especialmente si atendemos al hecho de que el monasterio de la Ferté se fundó en mayo de 1113, Pontigny en 1114 y Claraval en junio de 1115, todos a partir de la casa madre de Citeaux.

Pese a estas objeciones, es preciso reconocer que la cronología de 1167 cuadra bien con el contexto histórico, en un momento en el que Alfonso VIII estaba

\footnotetext{
${ }^{38}$ AHN, Clero, 569-20.

${ }^{39}$ Cartes, Fr. B. de. 1721: 120-122; González, J. 1960. El reino de Castilla en la época de Alfonso VIII: vol. II, 199-201, doc. 117. 1960.

${ }^{40}$ Álvarez Palenzuela, V. A. 1978: 112.

${ }^{41}$ Cartes, Fr. B. de. 1721: 97. 
empeñado en imponer su dominio sobre la zona del Tajo, frente a un enemigo interior como eran los Castro; esto se relaciona con el hecho de que en ciertas ocasiones los monarcas, en especial Alfonso VIII, utilizaron y promovieron las fundaciones cistercienses con la intención de reforzar su influencia en zonas en litigio; a eso obedecería la fundación de Monsalud en 1167. De hecho, el último estudio, que yo conozca, sobre el monasterio, el de Díaz Ibáñez, se inclina por la teoría de Álvarez Palenzuela; sitúa la fundación entre 1164 y 1167, considerando fundamental la donación realizada por el arcediano de Huete, quien habría actuado como colaborador de la realeza en el proceso de dotación del monasterio. $^{42}$

Estos argumentos de corte histórico no son concluyentes ni avanzan mucho en relación con la tradición epigráfica de esta inscripción. Eso no es óbice para que las dudas sobre ella, o mejor sobre los datos que transmite, sean más que razonables, aunque las afirmaciones tajantes sobre inscripciones desaparecidas me parecen harto peligrosas. La intitulación empleada, Ildephonsus septimus, confirma que el epígrafe no fue redactado en la época que marca su data, debido al uso del ordinal indicador del orden de sucesión junto al nombre del rey, no utilizado hasta mucho tiempo después. También sorprende el empleo del año del Señor. En 1140 hubiera sido mucho más lógico datar por la era hispánica. La datación por el Anno Domini no se generalizó en el reino castellano leonés hasta el siglo XIV, aunque es cierto que en ocasiones encontramos ejemplos anteriores. En toda la provincia de Guadalajara el primer epígrafe datado por el año de Cristo se da nada menos que un siglo después al de la inscripción que nos ocupa, corresponde a 1268 y se trata del epitafio necrológico del arcipreste de Atienza, actualmente desaparecido, por lo cual tampoco nos ofrece demasiada fiabilidad al respecto, que estuvo ubicado en la catedral de Sigüenza. ${ }^{43} \mathrm{El}$ primero conservado es la consecratio del propio monasterio de Monsalud, del 1282. No conocemos epígrafe alguno datado por el año de Cristo en el ámbito geográfico próximo que corresponda al siglo XII.

Estamos ante una inscripción redactada mucho tiempo después de los hechos que recuerda. De su existencia no considero que debamos dudar, dado el crédito que merece la obra de Ángel Manrique y el rigor y minuciosidad con la que trabajó; sí de los datos históricos que ofrece. No voy a entrar en la polémica cuestión del origen del monasterio, pues los principales argumentos de las teorías existentes han quedado esbozados en páginas precedentes, pero sí en la cuestión de la tradición epigráfica. Dependiendo de la idea que asumamos calificaremos a la inscripción de distinta manera. Si mantenemos lo aportado por

\footnotetext{
${ }^{42}$ Díaz Ibáñez, J. 1995: 368.

${ }^{43}$ Pérez Villamil, M. 1899. La catedral de Sigüenza: 395. Madrid.
} 
Cartes y el tumbo viejo, la definiremos como un original tardío. ${ }^{44} \mathrm{Si}$ optamos por seguir las ideas de Álvarez Palenzuela estaremos ante un falso..$^{45}$ Sea una u otra la respuesta, original tardío o falso, la intención de la inscripción no varía. Estaría en consonancia con la tradición de Monsalud, recogida por el tumbo y por Cartes, de acuerdo al pensamiento defendido por los monjes y que venía a ratificar la importancia y antigüedad del monasterio.

El documento aducido por Cartes en el que se inspiró la inscripción, supuestamente procedente de Escala Dei, daría respaldo jurídico a la tradición y la inscripción serviría para transmitirla de manera pública. Con esta intención, el abad ordenaría grabarla en piedra para avalar la tradición de Monsalud y transmitirla a las generaciones futuras de monjes a fin de cohesionar la propia comunidad y reforzar la importancia del monasterio.

Es exactamente lo mismo que se realiza en diversos pasajes del tumbo viejo. Podríamos incluso pensar en una realización coetánea. El tumbo fue escrito para conservar copia de los más importantes documentos del monasterio, algunos de ellos ya perdidos en un incendio, pero de los que se da noticia con objeto de preservar los privilegios y posesiones del cenobio, mientras la inscripción reivindica su antigüedad e importancia, también recogida en el tumbo. Parece haber cierta comunidad de intenciones e intereses, si bien es preciso constatar que uno y otra no fueron redactados por la misma persona, es decir fray Julián Martínez, hecho que se deriva del diferente ordinal empleado para referirse al mismo monarca, Alfonsus septimus en el caso de la inscripción y Alonso el octavo en el del Tumbo.

\section{LA CONSECRATIO ${ }^{46}$}

Se trata, sin duda, de la inscripción más interesante del monasterio. Esto no sólo por el interés que tiene cualquier epígrafe referente a la consagración, dada la trascendencia del acto litúrgico que recuerda y publicita de manera permanente, sino además por la escasez de consecrationes relativas a monasterios del Císter.

Esta rareza queda patente con una revisión de la magna obra de Ángel Manrique ${ }^{47}$ En ella realizó una minuciosa descripción de los monasterios,

\footnotetext{
${ }^{44}$ Son aquellas inscripciones «cuyo texto efectivamente llegó hasta nosotros tal y como salió de manos del autor pero los hechos que ellos se recogen son anteriores a su materialización» (García Lobo, V. y Martín López, M. E. 1995. De Epigrafía Medieval. Introducción y Álbum: 41. León).

${ }^{45}$ «Inscripciones cuyo mensaje y presentación no corresponde a lo que pretenden» (García Lobo, V. y Martín López, M. E. 1995: 43).

${ }^{46}$ Apéndice epigráfico, núm. 4.

${ }^{47}$ Manrique, A. 1642-1659.
} 
componiendo el más completo repertorio de inscripciones de monasterios cistercienses conocido, estudiado por la profesora Martín López. ${ }^{48}$ Recoge las inscripciones relativas al Císter, conservadas en España, Portugal, Alemania y Francia hasta 1236, un total de 142 ejemplares, de los cuales tan sólo cuatro son consecrationes, correspondientes a los monasterios de Tarouca (Portugal), de 1169, Claraval, de 1174, Claraval de Milán, de 1221, y San Anastasio de Roma, de 1222.

Ninguna de ellas procede de un monasterio hispano, lo cual realza la importancia del epígrafe que aquí estudiamos, pese a ser de fecha posterior. Tengamos en cuenta, para explicar esta escasez de consecrationes, que para los cistercienses el altar debía estar desprovisto de toda ornamentación y lujo; obviamente la inscripción consecratoria podía ser considerada como tal.

Además, la iglesia cisterciense estaba reservada exclusivamente a los monjes, novicios, conversos y a los siervos; por ello, serían éstos los únicos que leerían la inscripción y, por tanto, no resultaba preciso constatar permanentemente la idoneidad del templo para el culto. Añadamos que la consecratio servía también para perpetuar el recuerdo de la ceremonia, hecho importante para la comunidad cristiana, que lo celebraba y conmemoraba anualmente con una fiesta solemne. Obviamente, en las iglesias cistercienses, tal recuerdo no era preciso. A esto debemos agregar la escasez de inscripciones consecratorias a partir de los primeros años del siglo XIII. ${ }^{49}$

Todo este panorama esbozado realza, evidentemente, el interés del estudio de la consecratio de Nuestra Señora de Monsalud.

La inscripción se encuentra encastrada en la parte izquierda de uno de los ábsides laterales, el situado en el lado izquierdo del principal, rematando la nave del Evangelio de la iglesia. Sin duda, estuvo durante muchos años tapada por el encalado que solía cubrir los templos durante la Edad Moderna o por el retablo que sabemos se ubicó en ambos ábsides laterales, según se lee en el Inventario de bienes del monasterio, realizado en 1835 con ocasión de la Desamortización. ${ }^{50}$ Por ello Cartes, ni tampoco ninguna de las otras publicaciones referentes al monasterio, nos dio noticia del epígrafe. Ha sido necesario esperar hasta un tiempo relativamente reciente para encontrar mención de él en la bibliografía. En 1982 se acometió un proyecto integral de restauración en el que se limpiaron

${ }^{48}$ Martín López, M. E. 2007: 462-463; Martín López, M. E. 2009. «Les inscriptions médiévales dans les «Annales» de Manrique: contribution à la possibilité d'une épigraphie cistercienne». Cahiers de Civilisation Médiévale 52/208. 395-413.

${ }^{49}$ Martín López, M. E. 2010. «Las inscripciones diplomáticas en el período gótico» en Martín López, M. E. y García Lobo, V. (Coords.) Las inscripciones góticas. II Coloquio Internacional de Epigrafía Medieval: 103-104. León.

${ }^{50}$ Pérez Arribas, A. 1988. El monasterio de Monsalud en Córcoles. Guadalajara. 
y rasparon los paramentos y bóvedas de sillería, ${ }^{51}$ permitiendo sacar a la inscripción del olvido. Por eso el estudio, realizado en 1990 por Concepción Abad Castro sobre el conjunto y centrado, fundamentalmente, en cuestiones artísticas, supuso la publicación, por vez primera, de la consecratio, ${ }^{52}$ pero ofreciendo una transcripción incorrecta.

Su privilegiada posición y el uso de pintura roja y azul para remarcar las letras, cuyos restos aún pueden apreciarse en diversos puntos del epígrafe, especialmente en la parte superior, contribuyeron a la principal intención que, sin duda, tuvo el autor moral de la inscripción, probablemente el abad del monasterio,${ }^{53}$ cuando ordenó su realización: dotar de máxima visibilidad y legibilidad al texto que daba fe de la ceremonia de consagración del altar. Con tales elementos y la típica escritura epigráfica, también denominada publicitaria por García Lobo, ${ }^{54}$ se conseguía la difusión de la consagración, el recuerdo de la ceremonia y su fecha concreta entre todos los monjes que, diariamente, asistían a los oficios en la iglesia.

La estructura de la inscripción es la típica de las consecrationes medievales. Se indica la data, situada en primer lugar, a continuación la notificatio, con la directio, mostrando la advocación bajo la cual se coloca el altar, y la intitulatio, si bien únicamente se señala el cargo del consagrante, no su nombre, para culminar el texto con un inventarium de reliquias. No añado nada nuevo si indico que la uniformidad de la inscripción de Monsalud con otros epígrafes consecratorios es debida a la frecuente utilización de formularios en la redacción de estos textos publicitarios, atestiguada en numerosas ocasiones por los estudiosos de la Epigrafía, tanto para el mundo Antiguo como para el Medieval.

Resulta de interés el análisis de los diferentes elementos de la inscripción. Comencemos por la data. A pesar del mal estado de conservación de esa parte, aún se pueden apreciar antes del numeral las letras NI; eso hace indudable que la inscripción comenzó por la fórmula cronológica ANNO D(omi)NI. Como señalé al estudiar el monumentum dotationis, la forma de datar por el año del Señor comienza a extenderse en las inscripciones en la segunda mitad del siglo XIII, para generalizarse en el siguiente. En el caso del epígrafe que estudiamos esa expresión genérica al año del Señor esconde un uso del llamado estilo de la Encarnación en su cómputo florentino, que comienza el año el 25 de marzo

\footnotetext{
${ }^{51}$ El expediente de la restauración en Archivo General de la Administración, 26/781 y 26/782.

${ }^{52}$ Abad Castro, C. 1990: 47-73.

${ }^{53}$ No conocemos su nombre, ya que después de 1270, debido al incendio del archivo del monasterio, no se conserva la memoria de los abades. Tenemos una relación, procedente sobre todo del primer tumbo, pero al no tener las fechas concretas en que ejercieron el cargo resulta de poca utilidad para conocer quién era abad cuando se consagró el altar.

${ }^{54}$ García Lobo, V. 2010. «La escritura publicitaria» en Martín López, M. E. y García Lobo, V. (Coords.) Las inscripciones góticas. II Coloquio Internacional de Epigrafía Medieval: 29-44. León.
} 
después del nacimiento de Cristo. Esto es indudable visto el día indicado a continuación del año «tertio idus ianuari, videlicet dominica infra octauas Apparicionis $D$ (omi)ni», es decir el 11 de enero, domingo de la octava de la Aparición (la Epifanía) del Señor. Si se utiliza el cómputo florentino, dado que la fecha está comprendida entre el 1 de enero y el 25 de marzo, hemos de sumar un año al indicado en el documento para convertirlo a nuestro cómputo actual, por tanto 1282, año en el que el 11 de enero fue domingo, dato importante por cuanto las consagraciones siempre tenían lugar en domingo o en día de fiesta mayor.

Es cierto que la fórmula habitual para indicar el estilo de la Encarnación es Anno Incarnationis Domini, pero no lo es menos que son muy frecuentes las ocasiones en que esa teoría no se cumple y numerosos documentos e inscripciones, que emplean el estilo de la Encarnación, usan la genérica fórmula de Anno Domini, sin añadir ningún dato más.

El reciente estudio sobre cronología de José María de Francisco ofrece diversos documentos de la catedral de Burgos y del monasterio de las Huelgas en los que el uso cronológico es similar al de la inscripción de Monsalud. ${ }^{55}$

Por citar algún otro ejemplo de inscripciones, podemos referirnos a dos ejemplares del monasterio de San Miguel de Escalada, ambos de la segunda mitad del siglo XIII, en los que la influencia francesa lleva al uso de la data cristiana de acuerdo al estilo de la Encarnación y, como en ésta, en una de ellas la expresión utilizada es simplemente anno Domini. ${ }^{56}$

No sorprende su utilización, pese a la mayor frecuencia en Castilla del estilo de la Navidad, adoptado cuando se abandonó la datación por la era hispánica. Este estilo fue muy utilizado por la cancillería pontificia, lo cual repercute en su frecuente presencia en documentación emitida por instituciones eclesiásticas, además de ser también habitual en el reino de Francia, realidad que ha de tenerse en cuenta por la procedencia gascona de los fundadores del monasterio y el hecho de que, presumiblemente, los abades, hasta el siglo XIV, continuaron siéndolo. ${ }^{57}$ Esto también podría haber influido en el uso del año del Señor en una fecha relativamente temprana. Basta consultar otros documentos relacionados con el monasterio para comprobarlo; publica Cartes varios de ellos correspondientes al siglo XIII, en los cuales es habitual la data por el estilo de la Encarnación mencionado expresa o simplemente con el giro Anno Domini. ${ }^{58}$

\footnotetext{
${ }^{55}$ Francisco Olmos, J. M. de. 2010. Manual de cronología. La datación documental histórica en España: 180-181. Madrid.

${ }^{56}$ García Lobo, V. 1982. Las inscripciones de San Miguel de Escalada. Estudio crítico: núms. 27 y 29. Barcelona.

${ }^{57}$ Díaz Ibáñez, J. 2002. La iglesia de Cuenca en la Edad Media (Siglos XII-XV): estructura y relaciones de poder: 486 . Madrid.

${ }^{58}$ Cartes, Fr. B. de. 1721: 143-144.
} 
Es curiosa, por poco habitual en las inscripciones, la mención al día de la consagración mediante la expresión «dominica infra octavas apparicionis Domini». Obviamente las grandes fiestas y ciclos del calendario litúrgico de la Iglesia regulaban en buena medida la vida del hombre medieval, lo cual, como es lógico, se intensificaba aún más en un monasterio. Eso lleva a que, en numerosas ocasiones, la mención al día concreto del mes se referencie con alguna de esas grandes fiestas, ${ }^{59}$ en este caso la de la Epifanía del Señor. Aunque es un sistema de datación conocido y utilizado, no suele ser muy frecuente en las manifestaciones epigráficas, dado el carácter sintético que suele tener el lenguaje de las inscripciones para ahorrar espacio.

La directio que indica la advocación bajo la cual se coloca el altar tiene ciertas dificultades de interpretación por el mal estado de la inscripción. En ella se menciona a la Virgen, como suele ser habitual en los cenobios cistercienses, dado que los capítulos de 1119 y 1134 ordenaron que todos los monasterios fuesen fundados «en honor de la Reina de Cielo y Tierra» y que todos fuesen dedicados a Santa María. La Orden Cisterciense fue definida en un privilegio expedido por el Papa Gregorio X en 1284 como consagrada y diputada a la Reina de los Ángeles por la singular devoción que le tiene. ${ }^{60}$

La intitulatio menciona simplemente el cargo del consagrante, obviamente un obispo. Sin embargo elude su nombre concreto y su diócesis. Aunque cualquier obispo podía realizar la ceremonia de la consagración, generalmente las autoridades monásticas se dirigían al diocesano, para mantener la sumisión a la jerarquía. Por ello, lo presumible es que la ceremonia fuese oficiada por el obispo de Cuenca, en aquellos años don Gonzalo García Gudiel. Llama la atención la ausencia de su nombre. Puede deberse a haber sido el abad de Monsalud el autor moral de la inscripción y no considerar necesaria la inclusión del nombre personal del obispo, quizá en relación con la gran autonomía con respecto al obispo diocesano que el Papa Inocencio IV concedió a Monsalud algunos años antes de la consagración, en $1250 .{ }^{61}$

En lo que se refiere al inventarium de reliquias poco es lo que se puede añadir a lo que indica la misma inscripción. Cuando Cartes enumera las reliquias del monasterio, sin duda uno de sus bienes más preciados, no se refiere a ninguna de las constatadas en el epígrafe. Sorprende que el monasterio no conservara la memoria de las reliquias depositadas en el altar en el momento de su consagración, pues sin duda contribuían a su mayor grandeza. Los santos Mario, Marta, Audifax y Ábaco formaban parte de una familia persa que se convirtió al cristianismo; visitaron Roma con la intención de venerar las tumbas de los

\footnotetext{
${ }^{59}$ Francisco Olmos, J. M. de. 2010: 225-231.

${ }^{60}$ Manrique, A. 1613. Santoral cisterciense: hecho de varios discursos predicables en todas las fiestas de Nuestra Señora y otros santos: fol. 1. Barcelona.

${ }^{61}$ Díaz Ibáñez, J. 2002: 484. 
mártires, a pesar de la campaña de persecución de cristianos llevada a cabo por el emperador Claudio II. Fueron apresados por el gobernador Marciano por haber reunido las cenizas de los mártires quemados en el anfiteatro y haberlas enterrado. Gregorio de Espoleto fue apresado durante las persecuciones de Diocleciano por no querer hacer sacrificios a los dioses y por defender la adoración de un único Dios; murió mártir en el 303. Santa Petronila también corresponde a la época romana; fue enterrada en el cementerio de Domitila.

\section{LOS EPITAPHIA SEPULCRALIA}

Se conservan en Monsalud tres epitaphia sepulcralia, uno de ellos muy deteriorado y, a juzgar por los restos de escritura que aún conserva, bastante posterior desde el punto de vista cronológico. Muy relacionada con la producción epigráfica está la cuestión del posicionamiento de los cistercienses ante las sepulturas en los monasterios. Inicialmente se mostraron absolutamente contrarios a sepultar en sus monasterios a personas ajenas a la comunidad monástica, si bien la mayor parte de ellos terminaron sucumbiendo a los ingresos económicos que podían suponer los derechos de entierro de los notables de la sociedad. A veces, los poderosos, temerosos de la muerte y del más allá, entregaban sus bienes a algún monasterio, con la condición de ser alimentados y vestidos mientras viviesen, para recibir al morir idéntico tratamiento al de los monjes. ${ }^{62}$ En otras ocasiones realizaban generosas donaciones a cambio del privilegio de ser enterrados en el cenobio. Este tipo de solicitudes fue habitual desde el siglo XII y, lógicamente, tuvo repercusión en los usos funerarios.

El ritual funerario consistía en unas honras muy sencillas para todos los miembros de la comunidad, con la excepción del abad o de algún personaje significativo. Son usos que parecen poco compatibles con la presencia de inscripción en el sepulcro y, de hecho, el cuerpo se depositaba en el cementerio directamente en la fosa y cubierto simplemente por tierra. Pero este sencillo ritual fúnebre inicial fue enriqueciéndose $\mathrm{y}$, a la vez, relajando, como en tantas otras cosas, la rigidez de los primeros tiempos; es algo especialmente evidente ya en el siglo XIII. Tal evolución viene acompañada por la erección de ricos sepulcros y por la cada vez mayor presencia de inscripciones que exaltan las glorias y virtudes mundanas del finado. Los epitafios comienzan a formar parte del reconocimiento de la comunidad cisterciense hacia aquellos que con su generosidad han permitido gran parte del patrimonio del monasterio en cuestión y de las exigencias de estos mismos donatarios, que no se conformarán con el anonimato de una fosa en el cementerio y buscarán, no sólo la notoriedad

\footnotetext{
${ }^{62}$ Bango Torviso, I. G. 1998. «Un mundo para la eternidad» en Monjes y Monasterios. El Císter en el medievo de Castilla y León: 307. Valladolid.
} 
y pervivencia inmemorial, conseguida en ocasiones mediante el epígrafe, sino además la ubicación del sepulcro en un lugar privilegiado, ya fuese la iglesia, el claustro o el mismo cementerio con sus capillas y pórticos.

En el caso de Monsalud sabemos que a principios del siglo XVI don Álvaro de Luna, señor de Escamilla y cura de Tragacete, dejó estipulado en su testamento la entrega al monasterio a su muerte de sus heredades de Escamilla y Millana, pidiendo ser enterrado en la iglesia del monasterio y que el abad y convento rogasen a Dios por su alma. Don Álvaro falleció el 27 de septiembre de 1502 y fue enterrado en la iglesia de la abadía. Este noble fue considerado por los monjes de Monsalud como uno de los más importantes benefactores de la comunidad ${ }^{63}$ ¿Puede referirse a él la inscripción casi perdida situada en el claustro, en el muro anexo a la sala capitular (Apéndice epigráfico, núm. 5)? Inscripción de la que podemos decir muy poco dado su notorio deterioro; únicamente una aproximación a su cronología por el tipo de escritura utilizado, una gótica minúscula, que hemos de vincular con los siglos XV o XVI.

Las referencias a enterramientos en los claustros cistercienses son numerosas desde el siglo XIII, ya fuese en el suelo, en los muros o en los intercolumnios. También en las salas capitulares comenzó a ser habitual la presencia de enterramientos, generalmente de abades o abadesas, practicados en los muros laterales, en el suelo o en grandes tumbas exentas en el centro de la sala. Era la manera para que tanto vivos como muertos asistieran al capítulo y, de este modo, los abades ejercían su autoridad más allá de este mundo. También personajes de gran significación o unidos a la comunidad por algún vínculo podían recibir la distinción de ser enterrados allí.

En el caso de los dos caballeros calatravos cuyo epitafio aún se conserva en Monsalud, Nuño Pérez de Quiñones y Sancho de Fontova (Apéndice epigráfico, núms. 2 y 3), los epígrafes son testimonio de la relación de la Orden de Calatrava con el monasterio. Los monjes cistercienses consideraban hermanos a los religiosos-guerreros miembros de las órdenes militares y Calatrava desde muy pronto quedó afiliada e incorporada al Císter. Para el caso de Monsalud se ha discutido bastante la presencia de la Orden de Calatrava en el monasterio. Contamos con varios documentos que acreditan la relación entre la Orden y Monsalud. El primero es la donación a perpetuidad que realizó Alfonso VIII el 12 de marzo de 1174 de la abadía de Córcoles al maestre y frailes de Calatrava; poco después el rey hizo saber a sus súbditos la citada donación indicando «abbatiam de Corcolas cum hereditatibus suis et pertinentiis magistro de Calatrava et fratribus dedi iure habendam hereditario im perpetuum» ${ }^{64}$ Estos documentos ratifican la idea de la presencia de la Orden en Monsalud, lo cual no

${ }^{63}$ Díaz Ibáñez, J. 1995: 392-393.

${ }^{64}$ González, J. 1960: vol. II, 332, doc. 201; Díaz Ibáñez, J. 1995: 386-387.

Hispania Sacra, LXIV

129, enero-junio 2012, 67-96, ISSN: 0018-215-X, doi: 10.3989/hs.2012.003 
es de extrañar dada la proximidad del castillo de Zorita, dado por Alfonso VIII a Calatrava en el mismo año 1174.

Noticia concreta sobre los dos enterrados en Monsalud nos la ofrece una vez más Cartes, quien señala que después de la derrota de Alarcos don Nuño Pérez de Quiñones, maestre de la Orden, se retiró a la villa de Ciruelos, pero no considerándola segura trasladó el Sacro Convento a el de Monsalud. ${ }^{65}$ Probablemente de Cartes extrajo Layna sus datos cuando indicó que después del desastre de Alarcos, en 1195, y la toma por los almohades del castillo de Salvatierra, en 1211, parece que algunos caballeros de Calatrava buscaron asilo en Monsalud, acompañando a su maestre Nuño Pérez de Quiñones, quien renunció al maestrazgo y se retiró a este monasterio, donde murió y fue sepultado. ${ }^{66}$ En lo que se refiere a Sancho de Fontova dice Cartes que era persona de autoridad en la orden de Calatrava y que la tradición de Monsalud asegura haber sido comendador, ${ }^{67}$ de lo cual no tenemos constancia documental. La importancia de ambos queda acreditada, no sólo por las mismas inscripciones, sino también por la ubicación que tuvieron los sepulcros, en los espacios de las ventanas entre la sala capitular y el claustro. Indican asimismo los dos epígrafes la trascendencia que dio la comunidad de Monsalud a la eterna deposición en su monasterio de los restos de estos caballeros calatravos.

\section{LA ESCRITURA DE LAS INSCRIPCIONES}

De las cuatro inscripciones medievales aún hoy existentes en el monasterio de Monsalud, tres de ellas nos ofrecen una escritura gótica mayúscula, se trata de las tres correspondientes al siglo XIII, abarcando casi la totalidad del siglo, pues la más temprana supuestamente es de 1202 y la más tardía de 1282. La cuarta, como ya señalé antes, presenta una gótica minúscula que denota una cronología del siglo XV o del XVI, sin que sea posible hacer al respecto ninguna precisión más, dado su lamentable estado de conservación, que la torna en casi ilegible.

Es interesante el análisis escriturario ${ }^{68}$ de las tres datadas en el siglo XIII, con la intención de establecer la existencia o no de un scriptorium epigráfico en Monsalud o al menos de cierta identidad gráfica entre los tres letreros. Obvia-

\footnotetext{
${ }^{65}$ Cartes, Fr. B. de. 1721: 176-177.

${ }^{66}$ Layna Serrano, F. 2001. Arquitectura románica en Guadalajara: 257. Guadalajara.

${ }^{67}$ Cartes, Fr. B. de. 1721: 177.

${ }^{68}$ Prescindo en él del análisis del ángulo de escritura por considerar que poco aporta al estudio de una escritura en la mayoría de las ocasiones artificiosa, no manuscrita, una escritura que podríamos denominar de diseño, que no sale con naturalidad de la mano del escriba y en la que los contrastes entre trazos gruesos y finos responden más a cuestiones meramente ornamentales que a la posición del instrumento escriptorio sobre el soporte.
} 
mente entre ellas existen claras similitudes, como no podía ser de otro modo por el uso de la gótica mayúscula. Sin embargo, el análisis gráfico delata diferencias y permite aventurar para las dos más tempranas, especialmente para la primera, una cronología posterior a la que indican en su data.

La ejecución del epitafio de Nuño Pérez de Quiñones, datado en 1202, es, con diferencia, la más cuidada. Muestra una magnífica ordinatio, con un pautado separando los diferentes renglones que, probablemente, no sólo tuvo el fin utilitario de enmarcar las letras, sino al mismo tiempo decorativo y de llamada de atención al posible lector. Esa misma intención de notoriedad tuvo el contraste de trazos gruesos y finos, con tendencia a tener mayor grosor los trazos de disposición vertical e inferior los que la tienen horizontal. Utiliza interpunciones, basadas en dos puntos sobrepuestos de forma romboidal (en una ocasión es un punto dispuesto en el centro del renglón), de una manera un tanto anárquica, pues no aparecen en todos los espacios entre palabras. La forma de las letras, en consonancia con el resto de la inscripción, muestra una notable regularidad, utilizando el ordinator siempre la misma forma para cada letra. Destaca el hecho de la total ausencia de abreviaturas y de otro tipo de recursos gráficos, como pueden ser enlaces, cruzamientos o letras inscritas. La regularidad y cuidado con la que se realizó la inscripción se muestra de manera fehaciente en la relación modular de la escritura; la media de los cuatro renglones es 1,29 y la mayor diferencia entre ellos es de sólo 0,2 ${ }^{69}$ En esta inscripción llama la atención el uso de la gótica, ya que por cronología debería corresponder más una carolina, aunque evolucionada hacia la gótica, la que algunos autores han denominado escritura románica, ${ }^{70}$ de la cual tenemos algunos testimonios en la provincia de Guadalajara. Además se trata de una gótica bastante evolucionada con un elemento muy característico como es el cerramiento de determinadas letras, como la E, la F o la T.

Aspecto bastante diferente ofrece el epitaphium sepulcralis de Sancho de Fontova, datado en 1263. En primer lugar, la ordinatio es notoriamente menos cuidada, con letras desiguales, realizadas con mucha mayor naturalidad, como se observa en el hecho de que gran parte de ellas no ocupan la totalidad de la caja del renglón y otras la sobrepasan, bien por la parte superior, bien por la inferior. Como en la anterior inscripción, se aprecia el pautado original con el

\footnotetext{
${ }^{69}$ Para su cálculo he seguido el método aplicado por García Lobo, V. 1999. «La escritura publicitaria en la Península Ibérica, siglos XII-XIV» en Inschrift und Material, Inschrift und Buchschrift: 153. München, consistente en tomar como alto el espacio comprendido entre las líneas paralelas en que se inscriben las letras y como ancho lo resultante de dividir la longitud del renglón entre el número de letras y signos del mismo, considerando como tal las interpunciones que ocupan espacio, y no teniendo en cuenta las letras inscritas, que no lo hacen.

${ }^{70}$ Koch, W. 1996 «Inscripciones y estudios epigráficos de los países de lengua alemana», Estudios Humanísticos. Geografía, Historia, Arte 18: 172; Banti, O. 2000. «Dall'epigrafica romanica alla preumanistica. La scrittura epigrafica dal XII alla fine del XV secolo a Pisa», Scrittura e Civilta 24: 62.
} 
que se ayudó la ordinatio. Igualmente, presenta diferente grosor en los trazos verticales y horizontales de las letras. Aún conserva el coloreado en rojo del surco de las grafías, recurso eminentemente decorativo, buscando la mayor notoriedad posible del escrito. Utiliza interpunciones en todos los espacios entre palabras consistentes en puntos redondeados sobrepuestos. A pesar de la naturalidad en la ejecución de la escritura, la forma apenas muestra variación en las diferentes letras; la única significativa la ofrece la $\mathrm{T}$, que tiene una ejecución clásica, con dos trazos, y la muy típica de la gótica en la que el trazo vertical se incurva y se le añade otro también en forma de arco formando con el anterior una especie de $\mathrm{O}$. Cuenta con una única abreviatura, una $\mathrm{P}$ partida con valor de PER. En lo referente a la relación modular media, es algo superior a la del epitafio de Pérez de Quiñones, 1,69, pero denota mayor irregularidad, al igual que el resto de la inscripción, pues la mayor diferencia entre los renglones es de casi 0,5 .

La ordinatio del epígrafe de consagración muestra cierta desigualdad en la ejecución de las letras, aunque quizá no tan acusada como en el epitafio de Sancho de Fontova. Al igual que sucede en las otras dos inscripciones, también en ésta se aprecian aún las líneas de pautado utilizadas para separar los diferentes renglones; incluso puede observarse el pautado de dos líneas más en la parte inferior y un amplio espacio vacío, muestra de una ordinatio desajustada que no supo prever el espacio exacto que iba a tener el futuro texto. También como las anteriores la escritura parece utilizar el recurso decorativo del sombreado, con diferencia de grosor en los trazos de las letras, más gruesos los de dirección vertical que los horizontales; se observa al menos en algunas letras, si bien en otras resulta difícil afirmarlo por el deterioro del epígrafe. Presenta interpunciones en los espacios entre palabras, las del primer renglón consistentes en tres puntos sobrepuestos, las de los restantes únicamente dos. Es notoria la falta de homogeneidad en la forma de algunas letras.

Así la A tiene cinco formas distintas. La primera de ellas se caracteriza por cinco trazos, los dos externos no están unidos en el vértice, donde se dispone uno horizontal; además, el travesaño central de la letra se descompone en dos, en forma de V. La segunda es similar a la anterior, pero el travesaño se realiza con un único trazo horizontal. La tercera se asemeja a la típica A gótica seudouncial. La cuarta es parecida, pero el tramo curvo es el de la parte derecha de la letra. Por último, un tipo caracterizado por la ejecución curva de los dos trazos externos, dando a la letra un aspecto redondeado. En la D encontramos la típica letra gótica capital abombada en su parte superior e inferior y la D uncial. Dos son también los tipos de la M; el primero de ellos se ejecuta a partir de una O inicial, resultado de la unión de los dos primeros trazos de la letra, a la que se añade un tercero también curvo; el segundo tiene sus trazos curvos adquiriendo una forma uncial. La $\mathrm{N}$ presenta la típica forma uncial, estrangulando en 
ocasiones su segundo trazo, dando a la letra apariencia de R, y en algún caso adquiere una forma de trazos rectos en la que el central no arranca del vértice del primero, sino de su cuerpo. La T presenta la forma clásica compuesta por dos trazos rectos y otra, mucho más parecida a la de las otras dos inscripciones, en la que el trazo vertical tiene forma de arco y se añade a él un tercero con tendencia a cerrar el espacio. La U se realiza con forma uncial, con un trazo recto y otro curvo, o en su manera clásica, con dos trazos rectos que convergen en la parte inferior.

Las diversas abreviaturas de la inscripción están marcadas mediante una raya sobrepuesta. Los numerales ordinales de la fecha son señalados mediante una O sobrepuesta. La relación modular media es de 1,08, con mayor diferencia entre renglones de tan sólo 0,21. Esto da como resultado letras casi cuadradas, ligeramente más altas que anchas. Llama la atención que esto suceda en la inscripción aparentemente más tardía de las tres, pues parece contradecir la evolución conocida de la escritura epigráfica, dada la tendencia al alargamiento de las letras, y por ello aumento de la relación modular, que se experimenta en el siglo XIV. ${ }^{71}$ En esta inscripción hemos de citar también la utilización del recurso de las letras inscritas en los últimos renglones, aquellos en los que existen problemas de espacio; encontramos la I en el interior de la $\mathrm{D}, \mathrm{O}$ en el interior de $\mathrm{G}$ y, $\mathrm{O}$ en el interior de $\mathrm{P}$, es decir vocales en el interior de consonante que suele ser lo habitual. ${ }^{72}$

Las conclusiones que podemos extraer del análisis gráfico de las inscripciones es que, obviamente dada la distancia cronológica existente entre ellas, los autores materiales son distintos. Al mismo tiempo, creo que podemos intuir la inexistencia de un taller epigráfico en Monsalud, en función de la diversidad que caracteriza a los tres epígrafes y los diversos medios técnicos empleados en su ejecución, amén de las escasas inscripciones realizadas. Los epígrafes de Nuño Pérez de Quiñones y de Sancho de Fontova tienen notable parecido en sus formas gráficas, si bien la ejecución difiere, mucho más cuidada la de Pérez de Quiñones y más natural la de Fontova. Refleja el ordinator de este último menos dominio de la técnica epigráfica, con ciertas influencias de la escritura documental, como se observa perfectamente en la única abreviatura del texto, una P partida que cae por debajo de la caja del renglón.

La observación hecha acerca de la relación modular de las tres inscripciones lleva al planteamiento de una cuestión interesante. Ya antes cité como la consecratio tenía la más reducida de las tres, lo cual, como antes dije, parece

\footnotetext{
${ }^{71}$ En efecto, una de las características de la escritura gótica del siglo XIV es el alargamiento de las letras, que se tornan estrechas y se hacen casi el doble de altas que de anchas. Ver García Lobo, V. 1999: 179 y Koch, W. 1996: 176.

${ }^{72}$ Martín López, M. E. 2010. «La escritura gótica en las inscripciones» en M. J. Sanz Fuentes y M. Calleja Puerta, Las escrituras góticas desde 1250 hasta la imprenta: 135. Oviedo.
} 
contradecir la evolución de la escritura gótica epigráfica, sin que debamos dar a ello más valor que el de indicio. El análisis de las formas escriturarias de los epitaphia también apunta a una ejecución posterior a la indicada en su data. ${ }^{73}$ Así la E cerrada por la parte delantera comienza a utilizarse en la segunda mitad del siglo XIII, afirmación también válida para la $\mathrm{Z}$ de tres trazos similar a un 3 con la parte superior formada por rectas y para la $\mathrm{L}$ que incorpora un tercer trazo hacia arriba en paralelo al primero; algo antes, habría empezado a usarse la $\mathrm{T}$ de tres trazos, el segundo curvo prolongado hacia arriba por un tercero que, en ocasiones, incluso se cierra formando una O. En la misma línea está la F que une sus dos trazos horizontales por otro vertical, que en este caso se prolonga hasta la parte inferior del renglón. ${ }^{74}$ Todo esto puede llevar a pensar en una ejecución posterior a la de la fecha indicada en el propio epígrafe en el caso de ambos funera y situarla en años más próximos al XIV, si no en este mismo siglo, realidad más probable en el caso del epitafio de Pérez de Quiñones. Existe otro hecho que pudiera corroborar tal impresión. Se trata de la lengua utilizada, especialmente en lo referente esta última inscripción, datada en 1202 y redactada en romance. Parece ésta una fecha un poco temprana para una inscripción en castellano, pues es a partir de mediados del siglo XIII y sobre todo en el XIV cuando el latín deja paso al romance en la producción escrita. Con estos datos podríamos definir el epitafio de Nuño de Pérez de Quiñones como un original tardío. Me refiero a él como original tardío antes que como copia, debido a la falta de seguridad de la existencia de un original coetáneo a la muerte del maestre de Calatrava. Esta clasificación podría, quizá, aplicarse también a la inscripción de Sancho de Fontova, pero no existe ninguna seguridad al respecto.

\footnotetext{
${ }^{73}$ Me baso para ello en el minucioso estudio de Maximino Gutiérrez Álvarez, M. 1997. Zamora. Estudios en V. García Lobo (Dir.), Corpus Inscriptionum Hispaniae Mediaevalium I/2: 51-63. Turnhout.

${ }^{74}$ Para una caracterización general de la escritura del siglo XIV consultar el reciente trabajo de Martín López, M. E. 2010: 136-140.
} 


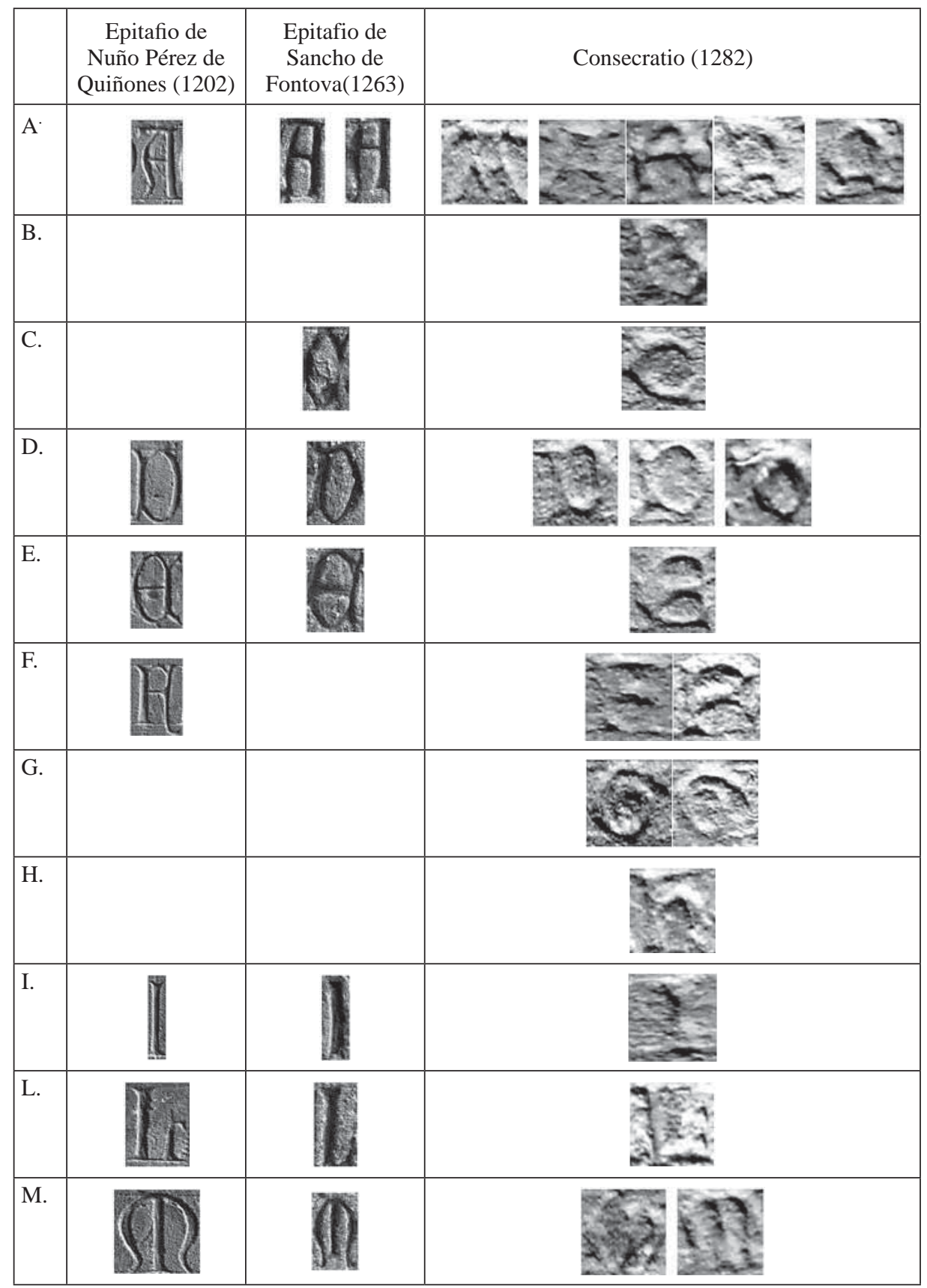

Hispania Sacra, LXIV

129, enero-junio 2012, 67-96, ISSN: 0018-215-X, doi: 10.3989/hs.2012.003 


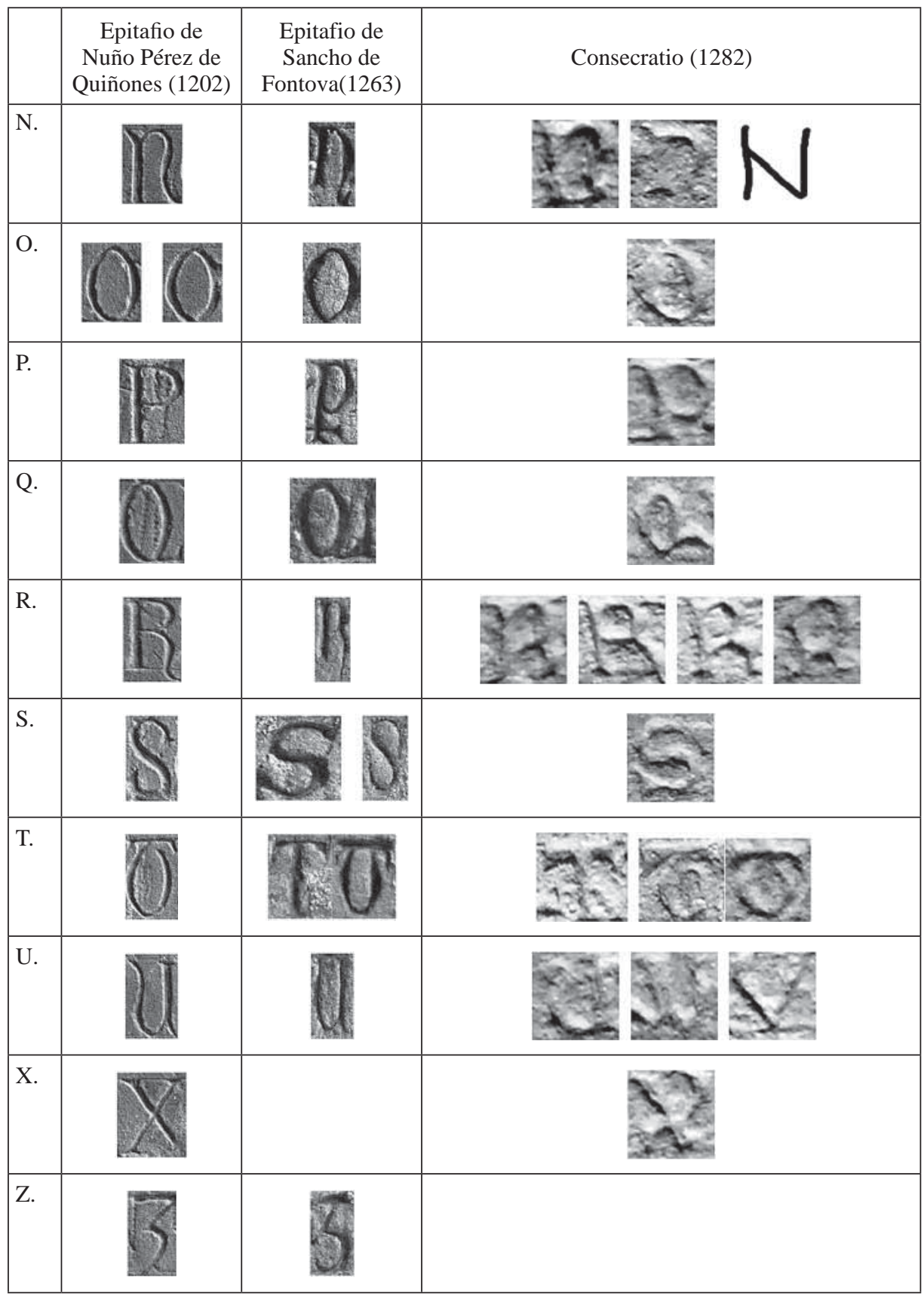


APÉNDICE EPIGRÁFICO

1. Roboratio del monasterio de Monsalud, 1140, 10 de noviembre.

CÓRCOLES, Monasterio de Monsalud, en la pared del Evangelio de la capilla mayor del monasterio, debajo de un escudo con las armas de Alfonso VII. Desaparecida. Falsa / original tardío.

PUBL.: Abad Castro, C. 1990: 48, n. 7; Álvarez Palenzuela, V. A. 1978: 112, n. 174; Cartes, Fr. B. de. 1721: 101; Manrique, A. 1642-1659: t. I, cap. IX, 1, fol. 415.

CIT.: Díaz Ibáñez, J. 1995: 365-366.

Ildefonsus septimus Rex, ac Hispaniarum Imperator, ob ingentia Montis salutis miracula, Deiparae, humilem, et antiquam domum insigni hoc Coenobio illustravit, donavitque familiae Cisterciensi, tunc mira sanctitate, ac religione florenti anno Domini M. CXL. quarto Idus Novembris

Ildefonsus septimus Rex ac Hispaniarum Imperator ob ingentia Montis Salutis miracula Deiparae humilem et antiquam domum insigni hoc coenobio illustravit donavitque familiae cisterciensi tunc mira sanctitate ac religione florenti, anno Domini M. CXL. quarto Idus Novembris

Alfonso VII, rey y emperador de las Españas, por los grandes milagros de la Santísima Virgen de Monsalud, convirtió una humilde y antigua casa en este insigne cenobio y lo donó a la familia cisterciense en aquel momento con asombrosa santidad y para florecimiento de la religión, en el año del Señor de mil ciento cuarenta, el día cuarto de los idus de noviembre.

2. Epitaphium sepulcrale de Nuño Pérez de Quiñones. 1202.

CÓRCOLES, Monasterio de Monsalud, en el lateral derecho de la ventana derecha situada entre el claustro y la sala capitular. Placa de arenisca; lo conservado tiene unas dimensiones de 52 x 23,5 cms. Escritura gótica. Fracturada en su parte izquierda. Original tardío.

PUBL.: Abad Castro, C. 1990: 72, nº 1; Cartes, Fr. B. de. 1721: 277; Díaz Ibáñez, J. 1995: 388; Pérez Arribas, A. 1988: 70.

CIT.: García Guinea, M. A. y Pérez González, J. M. (Dirs.). 2009. Enciclopedia del Románico. Guadalajara, vol. I: 386 y 392. Aguilar de Campoo; García de Paz, J. L.: 2003. Patrimonio desaparecido de Guadalajara: una guía para conocerlo y evocarlo: 137. Guadalajara; García López, J. C. y Pérez Villamil, M. 2002; Herrera Casado, A. 1988. Crónica y guía de la provincia de Guadalajara: 189. Guadalajara. 


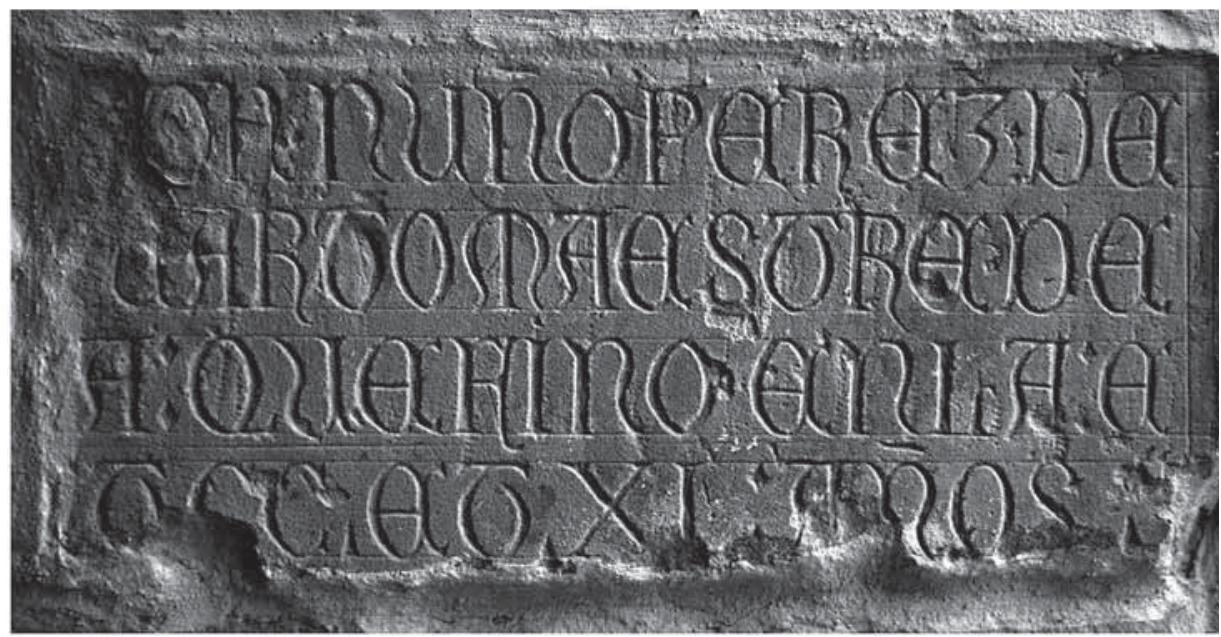

[AQUÍ YACE D]ON NUÑO PEREZ · DE [QVINONES Q]UARTO MAESTRE · DE [CALATRAV]A : QUE FINO EN LA : E [RA DE M] ET CC ET XL : AÑOS

Aquí yace don Nuño Pérez de / Quiñones, quarto maestre de I Calatrava, que finó en la e/ra de M et CC et XL annos.

Aquí yace don Nuño Pérez de Quiñones, cuarto maestre de Calatrava, que murió el año de la era de 1240 (1202 d.C.)

3. Epitaphium sepulcrale Sancho de Fontova. 1263, 7 de marzo.

CÓRCOLES, Monasterio de Monsalud, en el lateral derecho de la ventana izquierda situada entre el claustro y la sala capitular. Placa de arenisca; lo conservado tiene unas dimensiones de 45,5 x 27,5 cms. Escritura gótica. Fracturada en su parte derecha.

PUBL.: Abad Castro, C. 1990: 72, nº 2; Cartes, Fr. B. de. 1721: 721; Díaz Ibáñez, J. 1995: 389; Pérez Arribas, A. 1988: 70.

CIT.: García Guinea, M. A. y Pérez González, J. M. (Dirs.). 2009: 386 y 392; García de Paz, J. L.: 2003: 137; García López, J. C. y Pérez Villamil, M. 2002; Herrera Casado, A. 1988: 189. 


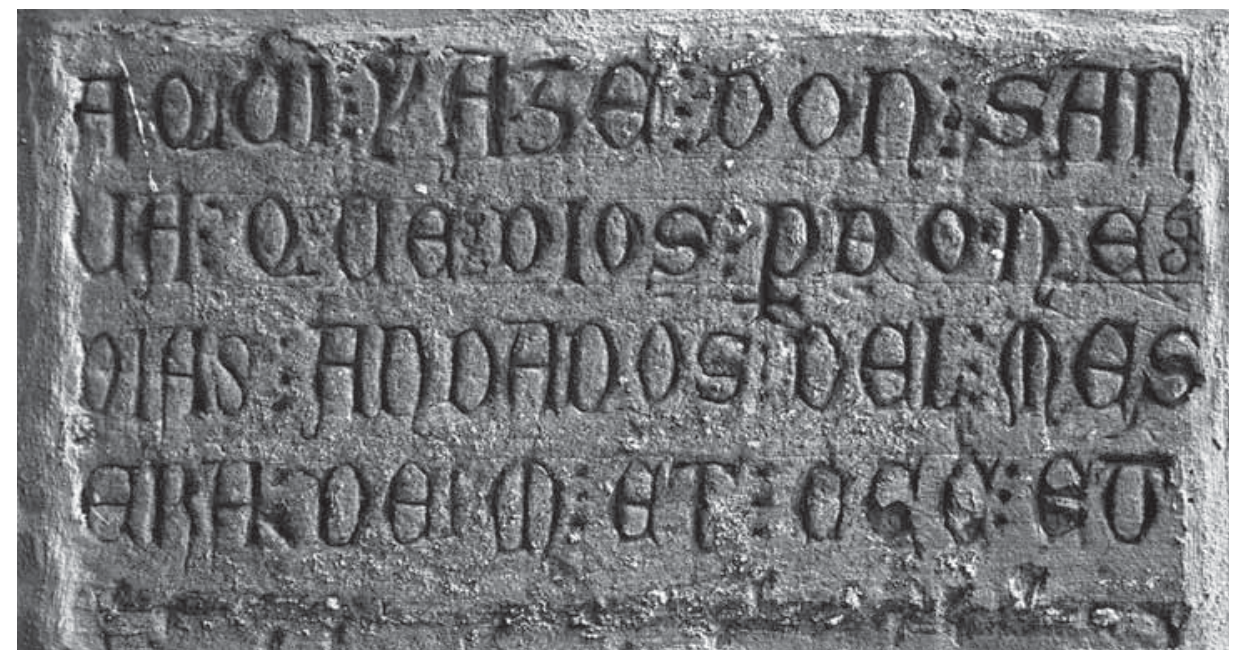

AQUI * YAZE * DON * SAN[CHO DE FONTO] UA * QUE * DIOS * PDONE [QUE FINO A VII] DIAS * ANDADOS * DEL * MES [DE MARZO DE LA] $\mathrm{ERA} * \mathrm{DE} * \mathrm{M} * \mathrm{ET} * \mathrm{CCC} * \mathrm{ET}[\mathrm{I}]$

Aquí yaze don Sancho de Fonto/va, que Dios p(er)done, que finó a VII días andados del mes de marzo de la era de M et CCC et I.

Aquí yace don Sancho de Fontova, que Dios perdone, que murió el día 7 de marzo de la era de 1301.

4. Monumentum consecrationis de un altar en el monasterio de Monsalud. 1282, 11 de enero.

CÓRCOLES, Monasterio de Monsalud, encastrada en un sillar del ábside norte. Arenisca con unas dimensiones de 78 x 39 cms. Escritura gótica. Regular conservación

PUBL.: Abad Castro, C. 1990: 72, nº 3.

[ANNO D]NI : Mo * CCo * OCTOGESIMO * PRIMO

T[E]RTIO : IDUS : IANUARII : UIDELICET : D[O]

MINICA : INFRA : OCTAUAS : APPARICIONIS : DNI :

CONSECRATU : $\mathrm{E}: \mathrm{HOC}:$ ALTARE : IN HONORE : SC[E]

5 BNIA DNO: MICAELE :DI : GRA : SCE : MARIE : D : ALGRA?

AB DNO : EPPO : IN QUO : CONTINTUR : RELIQIE : DE : /SEPUL 


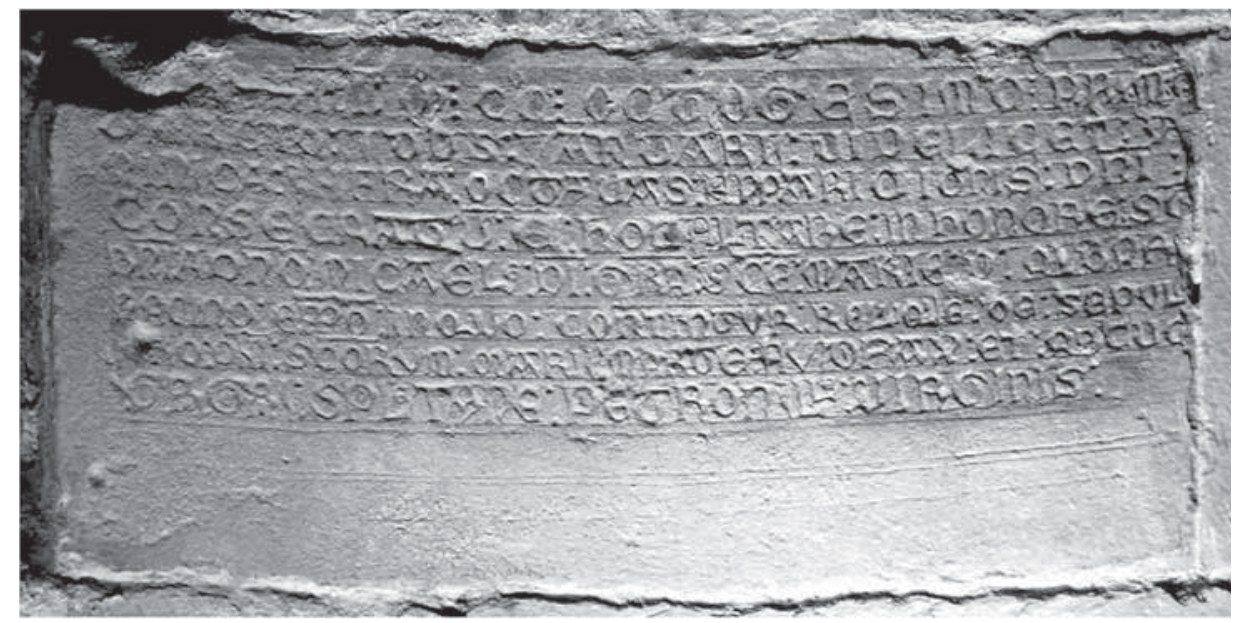

[CR]O DNI : SCORUM : MARII: MARTE : AUDIFAX : ET : IABCUC

GRGORII : SPOLETARE : PETRONILLE : UIRGINIS :

Las diferencias entre esta transcripción y la ofrecida por Abad Castro ${ }^{75}$ son sustanciales. Quedan reflejadas a continuación:

1.1: No transcribe nada antes del numeral del año; PRIM por PRIMO.

1.2: MO TODE SANCTUARII por T[E]RTIO : IDUS : IANUARII. RICIONIS

1.3: MI(NI)CE D HERA por MINICA INFRA; APARITIONIS por APPA-

1.4: CONSECRATU S por CONSECRATU E; IN HONORE S por IN HONORE SCE

1.5: $\mathrm{M}$ ( ) por BNIA DNO; OPAS por ALGRA.

1.6: PRIMO EMO MQUO por AB DNO EPPO IN QUO ET ABCUC.

1.7: S( ) por DNI; M( )RDE por MARTE; ()PAX FT CUO por AUDIFAX

1.8: SEPULTARE por SPOLETARE; PETRONILA por PETRONILLE.

Anno D(omi)ni MO CCO octogesimo primo / tertio idus ianuari, uidelicet do/minica infra octauas apparicionis D(omi)ni/, consecratu $(m)$ e (st) hoc altare in honore s(an)c(t)e ${ }^{\rho}$ Bnia?, d(omi)no Micaele, D(e)i gratia s(an) $c(t)$ e Marie d(e) Algra.../, ab d(omi)no ep(isco)po; in quo contin(en)tur

${ }^{75}$ Abad Castro, C. 1990: 72. 
reliq(u)ie de sepul/cro D(omi)ni, s(an)c(t)orum Marii, Marte, Audifax et Abcuc, Gr(e)gorii Spoletare, Petronille uirginis.

En el año del Señor de 1281, el día tercero de los idus de enero (11 de enero), es decir el primer domingo dentro de la octava de la aparición del Señor (la Epifanía), fue consagrado este altar en honor de santa ¿Bnia?, del señor Miguel y gracias a Dios de Santa María de Algra... por el señor obispo; en él se contienen las reliquas del sepulcro del Señor, de los santos Mario, Marta, Audifax y Ábaco, de Gregorio de Spoleto y de Petronila virgen.

\section{Epitaphium sepulcrale. Siglo XV ó XVI}

CÓRCOLES, Monasterio de Monsalud, en el claustro, en un sillar junto al arco de paso a la sala capitular, ocupando una extensión de 77 centímetros. Escritura gótica minúscula. Muy mal conservada. Inédita.

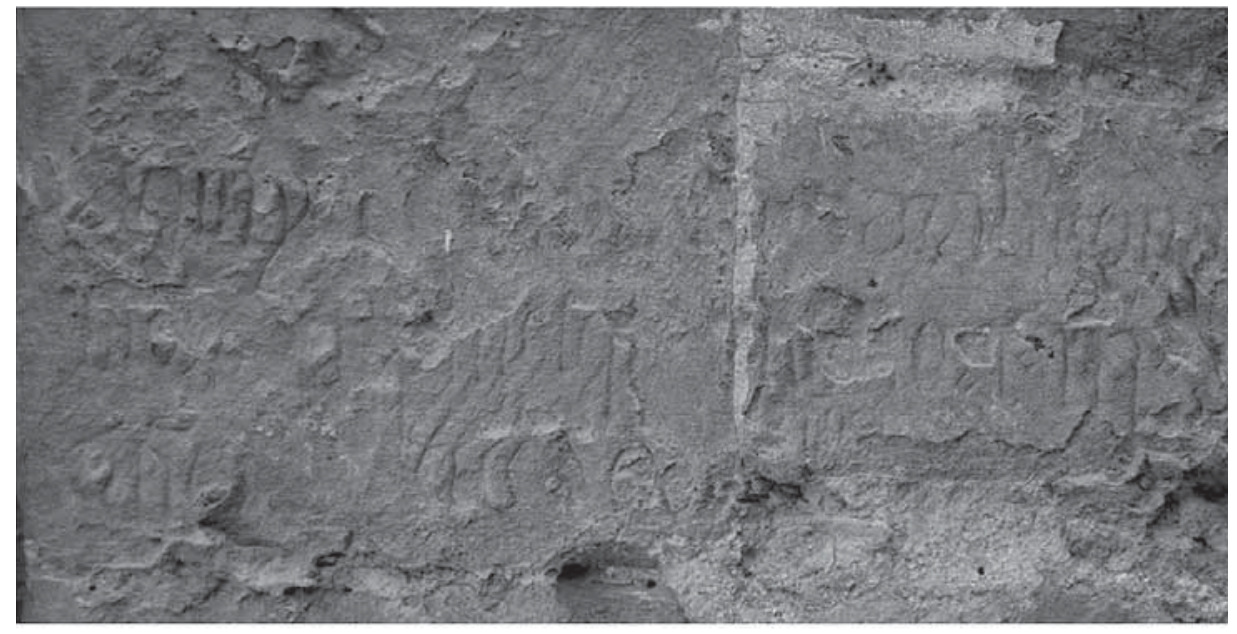

aqui y[ace ---] de ++++++++ q dios aia

$+++[---]+[]+.++q[---]$ s $[---]$

$[---]$

Aquí yace ... que Dios aya ... 


\section{BiBLIOGRAFÍA}

Abad Castro, C. 1990. «Monasterio de Monsalud de Córcoles (Guadalajara)». Anuario del Departamento de Historia y Teoría del Arte (U.A.M.) II: 47-74.

Álvarez Palenzuela, V. A. 1978. Monasterios cistercienses en Castilla (siglos XII-XIII). Valladolid: Universidad, Secretariado de publicaciones.

Bango Torviso, I. G. 1998. «Un mundo para la eternidad» en I. G. Bango Torviso (dir.), Monjes y Monasterios. El Císter en el medievo de Castilla y León: 307 . Valladolid: Junta de Castilla y León.

Banti, O. 2000. «Dall'epigrafica romanica alla pre-umanistica. La scrittura epigrafica dal XII alla fine del XV secolo a Pisa», Scrittura e Civilta 24: 61-101.

Cartes, Fr. B. de. 1721. Historia de la milagrosa imagen de Nuestra Señora de Monsalud. Alcalá.

Díaz Ibáñez, J. 1995. «Santa María de Monsalud. Reconstrucción histórica de un cenobio cisterciense», Cistercivm 201: 357-469.

Díaz Ibáñez, J. 2002. La iglesia de Cuenca en la Edad Media (Siglos XII-XV): estructura y relaciones de poder. Madrid: Universidad Complutense de Madrid.

Favreau, R. 1979. Les inscriptions médiévales. Turnhout: Brepols.

Francisco Olmos, J. M. de. 2010. Manual de cronología. La datación documental histórica en España: 180-181. Madrid: Ediciones Hidalguía.

García de Paz, J. L.: 2003. Patrimonio desaparecido de Guadalajara: una guía para conocerlo y evocarlo. Guadalajara: Aache.

García Guinea, M. A. y Pérez González, J. M. (Dirs.). 2009. Enciclopedia del Románico. Guadalajara, vol. I. Aguilar de Campoo: Centro de Estudios del Románico.

García Lobo, V. 1982. Las inscripciones de San Miguel de Escalada. Estudio crítico. Barcelona: Ediciones El Albir.

García Lobo, V. 1999. «La escritura publicitaria en la Península Ibérica, siglos XIIXIV» en Inschrift und Material, Inschrift und Buchschrift. München: Bayerischen Akademie der Wissenschaften.

García Lobo, V. 2010. «La escritura publicitaria» en Martín López, M. E. y García Lobo, V. (Coords.) Las inscripciones góticas. II Coloquio Internacional de Epigrafía Medieval. León: Corpus Inscriptionum Hispaniae Mediaevalium.

García Lobo, V. y Martín López, M. E. 1995. De Epigrafía Medieval. Introducción y Álbum: 41. León: Universidad.

García Lobo, V. y Martín López, M. E. 1998. «La publicidad en el Císter» en I. G. Bango Torviso (dir.), Monjes y monasterios. El Císter en el medievo de Castilla y León. Valladolid: Junta de Castilla y León.

García López, J. C. y Pérez Villamil, M. 2002. Relaciones Topográficas de la provincia de Guadalajara. Aumentos, Córcoles. Guadalajara: Aache [2 $2^{\mathrm{a}}$ edición en CD Rom; $1^{\text {a }}$ edición Madrid, 1908-1911].

González, J. 1960. El reino de Castilla en la época de Alfonso VIII. Madrid: Consejo Superior de Investigaciones Científicas.

Gutiérrez Álvarez, M. 1997. Zamora. Estudios en V. García Lobo (Dir.), Corpus Inscriptionum Hispaniae Mediaevalium I/2: 51-63. Turnhout: Brepols.

Herrera Casado, A. 1988. Crónica y guía de la provincia de Guadalajara. Guadalajara: Aache. 
Herrera Casado, A. 1997. Monasterios medievales de Guadalajara. Guadalajara: Aache.

Koch, W. 1996 «Inscripciones y estudios epigráficos de los países de lengua alemana», Estudios Humanísticos. Geografía, Historia, Arte 18: 161-182.

Layna Serrano, F. 2001. Arquitectura románica en la provincia de Guadalajara. Guadalajara: Aache.

Manrique, A. 1613: Santoral cisterciense: hecho de varios discursos predicables en todas las fiestas de Nuestra Señora y otros santos. Barcelona.

Manrique, A. 1642-1659. Cisterciensium seu verius ecclesiasticorum annalium a condito Cistercio. Lyon.

Martín López, M. E. 2007. «La publicidad en el nuevo monacato del siglo XII» en El monacato en los reinos de León y Castilla (siglos VII-XIII). Ávila: Fundación Sánchez Albornoz.

Martín López, M. E. 2009. «Les inscriptions médiévales dans les «Annales» de Manrique: contribution à la possibilité d'une épigraphie cistercienne». Cahiers de Civilisation Médiévale 52/208. 395-413.

Martín López, M. E. 2010. «Las inscripciones diplomáticas en el período gótico» en Martín López, M. E. y García Lobo, V. (Coords.) Las inscripciones góticas. II Coloquio Internacional de Epigrafía Medieval. León: Corpus Inscriptionum Hispaniae Mediaevalium.

Martín López, M. E. 2010. «La escritura gótica en las inscripciones» en M. J. Sanz Fuentes y M. Calleja Puerta, Las escrituras góticas desde 1250 hasta la imprenta. Oviedo: Universidad.

Martín López, M. E. y García Lobo, V. 2009. «La Epigrafía medieval en España. Por una tipología de las inscripciones» en J. C. Galende Díaz y J. de Santiago Fernández (dirs.), VIII Jornadas Científicas sobre Documentación de la Hispania altomedieval. Madrid: Universidad Complutense de Madrid.

Muñoz Párraga, M. C. 1998. «La iglesia» en Monjes y Monasterios. El Císter en el medievo de Castilla y León. Valladolid: Junta de Castilla y León.

Pérez Arribas, A. 1988. El monasterio de Monsalud en Córcoles. Guadalajara: Aache.

Pérez Villamil, M. 1899. La catedral de Sigüenza: 395. Madrid: Tipografía Herres.

Pérez-Embid, J. 1986. El Císter en Castilla y León. Monacato y dominios rurales (s. $X I I-X V)$. Valladolid: Junta de Castilla y León.

Yáñez, Fr. D. 1991. «En el milenario de Carracedo». Cistercivm XLIII/184: 23-72.

Yepes, Fr. A. de. 1960. Crónica General de la Orden de San Benito: vol. III. Madrid: Atlas [reedición de la edición de 1609-1621]. 